\title{
Transjugular Intrahepatic Portosystemic Shunt (TIPS): Pathophysiologic Basics, Actual Indications and Results with Review of the Literature
}

\section{Transjugulärer intrahepatischer porto-systemischer Stentshunt (TIPS): pathophysiologische Grundlagen, gegenwärtige Indikationen und Ergebnisse mit Review der Literatur}

Authors

Holger Strunk, Milka Marinova

\author{
Affiliation \\ Department of Radiology, Medical School \& Hospital, \\ University of Bonn, Germany \\ Key words \\ TIPS, porto-systemic shunt, stent-grafts, esophageal varices, \\ transhepatic, ascites
}

received 27.12 .2017

accepted 20.04.2018

\section{Bibliography}

DOI https://doi.org/10.1055/a-0628-7347

Published online: 2018

Fortschr Röntgenstr 2018; 190: 701-711

(C) Georg Thieme Verlag KG, Stuttgart · New York

ISSN 1438-9029

Correspondence

Prof. Dr. Holger Strunk

Department of Radiology, Radiologische Universitätsklinik

Bonn, Sigmund-Freud-Str. 25, 53105 Bonn, Germany

Tel.: ++49/2 28/2875992

Fax: $++49 / 228 / 2874449$

strunk@uni-bonn.de

\section{ABSTRACT}

Background Transjugular intrahepatic portosystemic shunt (TIPS) is a non-selective portosystemic shunt created using endovascular techniques. During recent years technical improvements and new insights into pathophysiology have modified indications for TIPS placement. In this article we therefore want to discuss current knowledge.

Method A literature review was performed to review and discuss the pathophysiology, indications and results of the TIPS procedure.

Results Established TIPS indications are persistent bleeding despite combined pharmacological and endoscopic therapy and rebleeding during the first five days. A new indication in the European recommendations is early TIPS placement within 72 hours, ideally within 24 hours, in patients bleeding from esophageal or gastroesophageal varices at high risk for treatment failure (e. g. Child-Pugh class $C<14$ points or Child-Pugh class B with active bleeding) after initial pharmacological and endoscopic therapy. For prevention of recurrent variceal hemorrhage in the recommendations, covered TIPS placement is the treatment of choice only after failed firstline therapy, although numerous TIPS studies show a prolonged time to rebleeding and a reduction of mortality. Similarly for secondary prophylaxis in patients with refractory ascites, covered TIPS placement may be considered only if the patient continues to be intolerant to NSBBs and is an appropriate TIPS candidate even though studies show that the TIPS procedure controls ascites, improves survival and renal function better than paracentesis. Potential indications for TIPS implantation are Budd-Chiari syndrome, acute portal vein thromboses, hydrothorax, hepatopulmonary and hepatorenal syndrome (Typ 2), portal hypertensive gastropathy (PHG) and prophylaxis of complications of abdominal surgery, very rarely bleeding in ectopic varices or in patients with chylothorax or chylous ascites.

Conclusion TIPS placement is an established procedure with a new indication as "early TIPS". In the European recommendations it is only the second-line therapy for prevention of recurrent variceal hemorrhage and for secondary prophylaxis in patients with refractory ascites although several studies showed a clear benefit of the TIPS procedure compared to ligation and NSBBs.

\section{Key Points}

- In addition to already established indications, new European recommendations suggest early TIPS placement in patients bleeding from esophageal or gastroesophageal varices at high risk for treatment failure.

\section{Citation Format}

- Strunk H, Marinova M, . Transjugular Intrahepatic Portosystemic Shunt (TIPS): Pathophysiologic Basics, Actual Indications and Results with Review of the Literature. Fortschr Röntgenstr 2018; 190: 701-711 


\section{ZUSAMMENFASSUNG}

Hintergrund Der transjuguläre intrahepatische portosystemische Shunt (TIPS) ist eine nicht operative Intervention zur Druckentlastung des Pfortadersystems. Technische Entwicklungen der letzten Jahre und erweiterte zugrundeliegende pathophysiologische Kenntnisse haben die Indikationen zur TIPS-Platzierung geändert. Im vorliegenden Review soll daher auf den gegenwertigen Kenntnisstand eingegangen werden.

Methode Dazu werden anhand der Literatur gegenwärtige Indikationen im Hinblick auf pathophysiologische Grundlagen, Indikationen und Ergebnisse aufgezeigt und diskutiert.

Ergebnisse Etablierte Indikationen für einen TIPS waren und sind die akute, endoskopisch nicht kontrollierbare Varizenblutung und die Re-Blutung innerhalb von 5 Tagen. Neu in die europäischen Empfehlungen aufgenommen wurde der Einsatz des TIPS in der Behandlung der akuten Ösophagus- und gastroösophagealen Varizenblutung als sogenannter „early TIPS“. Zur sekundären Blutungsprävention wird ein TIPS erst nach Versagen der Erstlinientherapie angegeben. Neuere Studien zeigen jedoch, dass durch die TIPS-Implantation eine Verlängerung des blutungsfreien Intervalls sowie Reduzierung der Mortalität möglich ist. Bei therapie-refraktärem Aszites wird ein TIPS nur bei den Patienten empfohlen, die nicht auf die Behandlung mit NSBB ansprechen, obwohl Studien gezeigt haben, dass durch den TIPS, verglichen mit der Paracentese, die glomeruläre Filtrationsrate steigt, der Aszites besser kontrolliert und das Überleben verbessert werden kann. Weitere mögliche Indikationen sind der Einsatz des TIPS beim Budd-Chiari-Syndrom, bei der akuten Pfortaderthrombose, beim Hydrothorax, dem hepatopulmonalen und hepatorenalen Syndrom (Typ 2), bei Patienten mit einer transfusionspflichtigen portalen hypertensiven Gastropathie sowie zur Prophylaxe von Komplikationen vor geplanten abdominellen operativen Eingriffen, selten bei Blutungen durch ektope Varizen oder bei Chylothorax bzw. chylösen Aszites.

Schlussfolgerung Der TIPS ist ein mittlerweile etabliertes Verfahren mit einer neuen Indikation als „early-TIPS“. Obwohl der bisherigen Therapie durch Ligation und Betablockern klar überlegen, steht er in den europäischen Empfehlungen bei der sekundären Prävention einer Blutung nur an zweiter Stelle, ebenso wie beim therapie-refraktären Aszites.

\section{Introduction}

The transjugular intrahepatic portosystemic shunt (TIPS) procedure is a nonsurgical intervention for relieving pressure in the portal venous system. In 1988 in Freiburg, M. Rössle used the method for the first time to treat portal hypertension [1]. While bare metal stents (BMS) were initially exclusively used, stents that are covered with polytetrafluorethylene (ePTFE) have increasingly been used in recent years. These stent grafts have a lower occlusion rate than bare metal stents and prevent clinical relapse [2]. Because of their similar patency rates to surgically placed shunts [3], they are currently primarily used.

In addition to these technical improvements, basic pathophysiological knowledge and thus also the indications for TIPS placement have expanded in recent years. Therefore, this article discusses the present state of knowledge, indications, technical aspects, complications, and criteria of patient selection.

\section{Basic pathophysiological principles}

The TIPS procedure is currently the only effective and fast option for lowering portal venous pressure. The method lowers the portal resistance, increases the portal venous inflow, and immediately decompresses the mesenteric venous congestion with a reduction in portal pressure of approximately $50 \%$. This reduction in portal pressure in connection with a fast increase in the effective arterial blood volume on the other side results in a significant improvement in the extrahepatic hemodynamic circulation within the first year [4]: the systemic activation of the vasoconstrictive system normalizes in the first 6 months and changes in the intracellular signal pathway (expression and activation of vasoactive proteins) in different vascular regions result in better vasoconstriction $[4,5]$.

In addition, the TIPS results in an improved hemodynamic response to the administration of non-selective beta blockers (NSBBs) possibly as a result of a change in signal transmission in the mesenteric vasculature. Since this response to NSBBs protects against variceal bleeding and results in a reduction of bacterial translocation and acute-to-chronic liver failure (ACLF), the TIPS procedure could also be useful for overcoming pathophysiological mechanisms in liver cirrhosis patients with pronounced portal hypertension which otherwise makes treatment with NSBBs ineffective. Therefore, it was able to be shown that NSBBs are ineffective in patients without clinical symptoms of significant portal hypertension [6] and that patients with severe vascular dysfunction are more likely to respond to NSBBs [5]. The TIPS procedure corrects the vascular dysfunction and can thus enhance the benefit of NSBBs. In this way the TIPS procedure may be able to make treatment with NSBBs possible. However, it is currently unclear whether the administration of NSBBs should be continued in these patients after a TIPS procedure or only in specific situations (e.g. portocaval pressure gradient after TIPS procedure $>12 \mathrm{~mm} \mathrm{Hg}$ ).

While the effects on the systemic and local vasoactive system are observed 6 months after a TIPS procedure, improvement in renal function and a decrease in bacterial translocation and systemic inflammation are already seen after 2 weeks $[7,8]$. The immediate increase in the effective blood volume due to placement of the TIPS stent improves renal perfusion and sodium elimination, controls ascites, and reverses hepatorenal syndrome $[8,9]$. Verifiable biochemical improvements affect the level of endotoxins, soluble tumor necrosis factor receptors (TNFR), and C-X-C motif chemokine ligands CXCL11 and CXCL9. Even if not 
yet fully understood, these data show a direct pathophysiological relationship between hemodynamic and immunological changes.

\section{Indications}

The European recommendations were published in 2015 in the Baveno Paper [10]. Established indications for a TIPS procedure were and are primarily acute variceal bleeding that cannot be controlled endoscopically and rebleeding within 5 days [10 - 12].

The use of TIPS to treat acute esophageal and gastroesophageal variceal bleeding as so-called "early TIPS" was newly included in the recommendations [10]. In patients with a relatively high risk of treatment failure (e.g. patients with Child-Pugh stage $C<14$ points or Child-Pugh stage B with active bleeding), the early TIPS procedure should be performed after initial pharmacological and endoscopic treatment within the first 72 hours, ideally within the first 24 hours. Therefore, multiple studies were able to show a significantly lower rebleeding rate and a survival advantage compared to combination therapy (pharmacological plus endoscopic therapy) as a result of a TIPS procedure in these patients [12 - 16].

After the occurrence of bleeding, patients who do not receive therapy have probability of rebleeding of $60-70 \%$ with a mortality rate of approximately $40 \%$. For secondary prevention, endoscopic ligature in combination with the administration of nonselective beta blockers (e.g. propranolol, nadolol) is specified as a first-line treatment [10]. As a result, the risk of rebleeding can be lowered to $40-50 \%$ and the mortality rate to $20-35 \%$. In the case of failure of the above-mentioned therapy, TIPS placement with use of a stent graft is the method of choice. However, more recent studies have shown that TIPS implantation compared to the above-mentioned therapy further extends the bleedingfree interval and reduces the mortality rate (10 - $20 \%$ rebleeding, $20-30 \%$ mortality) also in patients not responding to medication [17]. However, the higher rate of encephalopathy after a TIPS procedure ( $18 \%$ versus $8 \%$ ) is a disadvantage [17].

Interestingly, the use of the TIPS procedure in patients with treatment-refractory ascites is only considered in patients who do not respond to treatment with NSBBs [10] even though studies have shown that the glomerular filtration rate increases [8], ascites is better controlled, and survival can be improved with the TIPS procedure compared to paracentesis [18].

Budd-Chiari Syndrome (BCS) is also considered an indication for TIPS placement with a covered stent in patients who do not show any improvement when treated with medication with the procedure resulting in transplantation-free survival rates of $88 \%$ and $69 \%$ after 1 and 10 years, respectively $[11,19]$. Various studies have shown that TIPS placement can have a significant and highly individual effect on the mortality and clinical symptoms of patients with portal hypertension [12, 20]. Even though TIPS placement yields very good results even in high-risk patients, it must be taken into consideration that very poor liver function in the case of BCS can have a lethal outcome. A risk prediction can be made based on the Garcia-Pagan Score [19] that is calculated according to the formula: Age (years) $\times 0.08+$ bilirubin $(\mathrm{mg} / \mathrm{dl})$ $\times 0.16+$ INR $\times 0.63$. There is a high probability that patients with a score $>7$ will die or require liver transplantation after TIPS place- ment [10]. In patients with BCS, concomitant heparin-induced thrombocytopenia (HIT) is additionally seen in approximately $30 \%$ of cases. Therefore, HIT should always be excluded prior to TIPS placement in BCS.

The use of the TIPS procedure in acute portal vein thrombosis possibly combined with intravascular catheter lysis [21, 22], in the case of hydrothorax, hepatopulmonary syndrome, and hepatorenal syndrome (type 2) [23, 24] and for prophylaxis of complications prior to planned abdominal surgery has not been proven. Additional rarer indications are bleeding in ectopic varices and hypertensive gastropathy [10] or the treatment of a chylothorax or chylous ascites [25].

The current absolute contraindications for TIPS implantation according to the AASLD (American Association for the Study of Liver Diseases) [11] are:

- Right heart failure

- Liver cysts in the puncture path

- Uncontrolled systemic inflammation or sepsis

- Untreated bile duct obstruction

- Severe pulmonary hypertension (> $45 \mathrm{~mm} \mathrm{Hg}$ )

Relative contraindications are:

- Hepatocellular carcinoma, particularly in a central location

- Occlusion of all hepatic veins

- Portal vein thrombosis

- Severe coagulopathy (INR >5)

- Thrombocytopenia $<20000 / \mathrm{cm}^{3}$

- Moderate pulmonary hypertension

In addition, the indication for TIPS implantation in patients with a MELD $>15-18$ or bilirubin $>4 \mathrm{mg} / \mathrm{dl}$ must be viewed very conservatively and should only be performed after other treatment options have been tried. A Child-Pugh Score $>13$ points is viewed as an absolute contraindication while a score of $11-13$ points is viewed as a relative contraindication.

- Table 1 summarizes the general absolute and relative contraindications and the recognized as well as not yet generally accepted indications.

\section{Technical implementation}

Since multiple reviews have already described TIPS placement step-by-step [26 - 28], only a few points will be discussed here.

One of the technical difficulties associated with complications in many studies in TIPS placement is the puncture of a portal vein branch from the hepatic vein. At the turn of the millennium, this was usually performed under fluoroscopy either without (i. e., more or less blind) or with angiographic visualization of the portal vein system via wedge angiography with $\mathrm{CO}_{2}$ or iodine-containing contrast agent. Recent technical improvements have resulted in a number of possibilities regarding image guidance with an improved success rate and lower complication rate such as percutaneous or intravascular ultrasound guidance, direct transhepatic puncture of a portal vein branch and contrast injection as well as the use of cone-beam CT (CBCT), e.g. in the portal-venous phase 
- Table 1 Overview of indications and contraindications for TIPS placement modified according to AASLD (American Association for the Study of Liver Diseases) [11] and the Baveno Paper [10]. (Evidence level 1 - 5 (1 high, 5 low), recommendation level A-D (A strong, D weak).

\begin{tabular}{|c|c|c|c|}
\hline classification & indication/contraindication & Comments & $\begin{array}{l}\text { [11] or evidence/ } \\
\text { recommendation level [10] }\end{array}$ \\
\hline \multirow[t]{9}{*}{$\begin{array}{l}\text { general contraindications, } \\
\text { absolute }\end{array}$} & $\begin{array}{l}\text { severe and increasing restriction of liver function } \\
\text { (MELD Score }>15-18 \text {, serum bilirubin }>4.0 \mathrm{mg} / \mathrm{dl} \text {, } \\
\text { Child-Pugh Score }>13 \text { points). }\end{array}$ & $\begin{array}{l}\text { due to the high risk, the TIPS proce- } \\
\text { dure may only be performed in the } \\
\text { case of a lack of other treatment } \\
\text { options }\end{array}$ & \\
\hline & severe hepatic encephalopathy & & \\
\hline & $\begin{array}{l}\text { liver cysts in the puncture path, polycystic liver } \\
\text { disease }\end{array}$ & & according to AASLD \\
\hline & uncontrolled systemic inflammation or sepsis & & according to AASLD \\
\hline & untreated bile duct obstruction & & according to AASLD \\
\hline & severe pulmonary hypertension (> $45 \mathrm{~mm} \mathrm{Hg}$ ) & & according to AASLD \\
\hline & severe right heart insufficiency & $\begin{array}{l}\text { high mortality rate due to increased } \\
\text { right heart volume load after TIPS } \\
\text { placement }\end{array}$ & according to AASLD \\
\hline & insufficient arterial perfusion of the liver & & \\
\hline & $\begin{array}{l}\text { portal vein thrombosis with cavernous } \\
\text { transformation }\end{array}$ & $\begin{array}{l}\text { unless a large-caliber collateral suita- } \\
\text { ble for TIPS placement is present }\end{array}$ & \\
\hline \multirow[t]{7}{*}{$\begin{array}{l}\text { general contraindications, } \\
\text { relative }\end{array}$} & $\begin{array}{l}\text { limited liver function (Child-Pugh Score } 12 \text { - } 13 \\
\text { points) }\end{array}$ & & \\
\hline & $\begin{array}{l}\text { tumors (hepatocellular carcinoma, liver cysts), } \\
\text { particularly when in the planned TIPS tract or in } \\
\text { a central location }\end{array}$ & & according to AASLD \\
\hline & occlusion of all hepatic veins & $\begin{array}{l}\text { TIPS between inferior vena cava and } \\
\text { portal vein branch if applicable }\end{array}$ & according to AASLD \\
\hline & spontaneous bacterial peritonitis & after $7-10$ days of antibiotics & \\
\hline & $\begin{array}{l}\text { severe coagulopathy (INR }>5 \text { ), thrombocytopenia } \\
<20000 / \mathrm{cm}^{3}\end{array}$ & $\begin{array}{l}\text { except for in acute variceal bleeding } \\
\text { that cannot be controlled endoscopi- } \\
\text { cally }\end{array}$ & according to AASLD \\
\hline & $\begin{array}{l}\text { moderate pulmonary hypertension and hepato- } \\
\text { pulmonary syndrome }\end{array}$ & & according to AASLD \\
\hline & hepatorenal syndrome (HRS type II) & & \\
\hline \multirow[t]{6}{*}{ confirmed indications } & $\begin{array}{l}\text { acute variceal bleeding that cannot be controlled } \\
\text { via endoscopy in portal hypertension }\end{array}$ & & 2b; B \\
\hline & $\begin{array}{l}\text { "early TIPS" in acute esophageal and gastro- } \\
\text { esophageal variceal bleeding }\end{array}$ & $\begin{array}{l}\text { in patients with a relatively high risk } \\
\text { of treatment failure after initial phar- } \\
\text { macological and endoscopic treat- } \\
\text { ment }\end{array}$ & $1 \mathrm{~b} ; \mathrm{A}$ \\
\hline & variceal rebleeding within 5 days & & $2 \mathrm{~b} ; \mathrm{B}$ \\
\hline & $\begin{array}{l}\text { prevention of rebleeding in the case of failure of } \\
\text { first-line therapy }\end{array}$ & $\begin{array}{l}\text { first-line therapy: endoscopic ligature } \\
\text { in combination with administration } \\
\text { of nonselective beta blockers }\end{array}$ & $2 \mathrm{~b} ; \mathrm{B}$ \\
\hline & treatment-refractory ascites & $\begin{array}{l}\text { currently only in patients not re- } \\
\text { sponding to treatment with NSBBs } \\
\text { (but should be changed since TIPS } \\
\text { procedure improves transplantation- } \\
\text { free survival rate) or as a bridging } \\
\text { treatment prior to liver transplanta- } \\
\text { tion }\end{array}$ & $5 ; D$ \\
\hline & Budd-Chiari Syndrome (BCS) & $\begin{array}{l}\text { in the case of failure of treatment } \\
\text { with medication }\end{array}$ & $4 ; C$ \\
\hline
\end{tabular}


- Table 1 (Continuation)

\begin{tabular}{|c|c|c|c|}
\hline \multirow[t]{4}{*}{ classification } & indication/contraindication & Comments & $\begin{array}{l}\text { [11] or evidence/ } \\
\text { recommendation level [10] }\end{array}$ \\
\hline & & $\begin{array}{l}\text { not in patients with Garcia-Pagan } \\
\text { Score }>7\end{array}$ & $3 b ; B$ \\
\hline & $\begin{array}{l}\text { bleeding in ectopic varices and hypertensive } \\
\text { gastropathy }\end{array}$ & $\begin{array}{l}\text { in patients requiring transfusion and } \\
\text { failure of endoscopic ligature and/or } \\
\text { nonselective beta blockers }\end{array}$ & $4 ; C$ \\
\hline & $\begin{array}{l}\text { repeated variceal bleeding in patients with liver } \\
\text { cirrhosis and portal hypertension }\end{array}$ & $\begin{array}{l}\text { if technically possible and there is a } \\
\text { sufficient hepatic reserve }\end{array}$ & \\
\hline \multirow[t]{7}{*}{$\begin{array}{l}\text { controversial/currently } \\
\text { not generally recommen- } \\
\text { ded indications }\end{array}$} & prevention of rebleeding as first-line therapy & $\begin{array}{l}\text { compared with current first-line } \\
\text { therapy, TIPS extends the bleeding- } \\
\text { free interval and reduces the mortal- } \\
\text { ity rate }\end{array}$ & \\
\hline & extrahepatic portal vein thrombosis & $\begin{array}{l}\text { except for in additionally planned } \\
\text { intravascular catheter lysis }\end{array}$ & $\begin{array}{l}\text { relative contraindication } \\
\text { according to AASLD }\end{array}$ \\
\hline & recurrent pleural effusion/chylothorax & $\begin{array}{l}\text { patients can benefit in individual } \\
\text { cases, possibly as a bridging treat- } \\
\text { ment prior to liver transplantation }\end{array}$ & \\
\hline & hepatorenal syndrome (HRS type I) & $\begin{array}{l}\text { TIPS does not improve survival, as } \\
\text { bridging prior to liver transplantation }\end{array}$ & \\
\hline & $\begin{array}{l}\text { prophylaxis of complications prior to planned } \\
\text { abdominal surgery }\end{array}$ & & \\
\hline & hepatic veno-occlusive disease (VOD) & & \\
\hline & $\begin{array}{l}\text { patients with liver cirrhosis with pronounced } \\
\text { portal hypertension for improvement of response } \\
\text { to NSBBs }\end{array}$ & & \\
\hline
\end{tabular}

after i. v. contrast injection or in combination with image fusion techniques after preceding CT or mesenteric angiography.

In our opinion, percutaneous ultrasound-guided puncture is the best and easiest method and does not require radiation exposure ( $\triangleright$ Fig. 1,2$)$. It requires a hollow needle via which a guidewire can be inserted. After cannulating a hepatic vein, typically the right one, ultrasonography is used to determine whether this vein provides suitable access to a right-sided portal vein branch. If not, another hepatic vein should be probed ( $\boldsymbol{F}$ Fig. 1). It is very important to select a suitable hepatic vein even if it takes a while, because it makes the procedure significantly easier. The presence of a guidewire in the catheter improves the visibility of the catheter on ultrasound. Under ultrasonographic guidance from the flank and intermittent fluoroscopy guidance from a ventral approach, a right-sided portal vein branch is punctured ( $\triangleright$ Fig. 2) and cannulated with a guidewire and a catheter is inserted.

Following angiographic verification that a portal vein branch was punctured and that from this puncture site the main portal vein may be accessible, the portal vein is probed. The further procedure is then independent of the type of image guidance ( $\vee$ Fig. 3).

Ultrasound-guided puncture also has the advantage that even a thrombosed portal vein or a larger collateral in the case of cavernous transformation can be punctured.

A variant of the above-described "classic" TIPS procedure is the direct intrahepatic portocaval shunt (DIPS) procedure in which, for example, a side-to-side shunt is established under endovascular ultrasound guidance (via femoral artery) through the caudate lobe as the parenchymal tract [28]. Another possibility is to use ultrasound-guided puncture, e. g. from right lateral, to insert a needle through a large (right-sided) intraparenchymal portal vein branch into a central hepatic vein or the part of the inferior vena cava near the confluence. A guidewire is then inserted via this needle, captured and withdrawn with a snare introduced by jugular vein access. Using this wire running now from right lateral flank to jugular, a large-bore catheter or a sheath can be introduced jugular and via parenchymal tract is advanced into the punctured portal vein branch and the main portal vein in a central direction. Then the parenchymal tract is dilated and stented [29]. The main indication for these variants is the establishment of a TIPS in BuddChiari Syndrome [30].

\section{Embolization of varices}

There is general consensus that the embolization of visible collateral vessels reduces the rebleeding rate and improves shunt function in patients with bleeding of the esophageal varices [31] and that the embolization of collaterals persisting after TIPS placement improves clinical outcome [32]. However, the extent to which all collateral vessels are to embolized has not been clarified. We use an indication-dependent procedure: after the occurrence of bleeding, all visible collateral vessels are embolized; in the case 

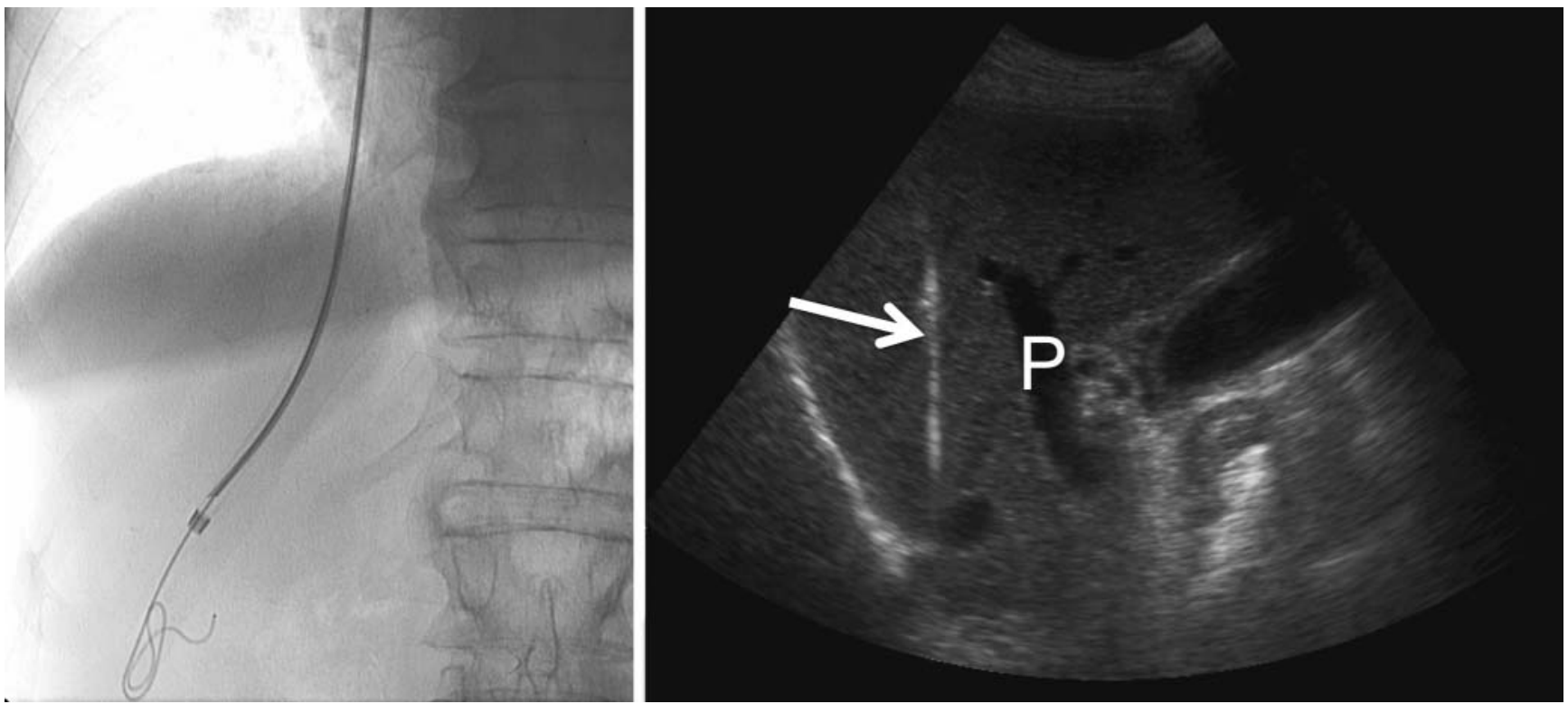

- Fig. 1 TIPS placement. Left image: After cannulation of a liver vein, a stiff guidewire is introduced allowing much better visualization by ultrasonography than with a hydrophilic coated guide wire. Right image: Ultrasonography from the right lateral position is performed to check for a suitable puncture track from this liver vein (arrow) to the portal vein branch (P).

of "treatment-refractory ascites", only collaterals persisting after TIPS stent placement are embolized.

It is also unclear whether embolization is to be performed before or after stent release. The advantage of embolization prior to release is the easier identification of collaterals. However, a possible disadvantage is the potential spreading of the embolic agent due to the faster flow. Coils and adhesives (Histoacryl) are primarily used for embolization. Coils allow highly controlled application but only proximal occlusion. In contrast, almost complete filling of the varices can be achieved with adhesive but the injection is less easily controlled.

The main indications for TIPS revision are

- Stenoses in the efferent hepatic vein

- Stenoses at the stent entry (rare in currently used stent grafts)

- Unfavorable TIPS anatomy or kink

- Coagulation disorder.

Depending on the situation, another balloon dilatation procedure, stent extension or in individual cases even the placement of a second TIPS tract is considered.

\section{TIPS reduction}

If it turns out that the selected TIPS diameter is too large (e.g. the patient develops encephalopathy or right heart failure), the following three TIPS reduction options are available:

- Positioning of a second balloon-expanded stent with a smaller diameter in the already placed TIPS stent. The space between the already placed external stent and the newly placed one can be embolized if needed using coils for example.

- Use of a special reducing stent

- Use of the sheath control technique [33] in which a covered stent graft with adaptable waist is inserted into the TIPS stent.
This can be pressed proximally and distally onto the stent. Exact calibration of the portosystemic gradients is possible in the middle by means of incremental expansion.

\section{Results}

The primary technical success rate of TIPS implantation is approximately $98 \%$ with a fatality rate of less than $1 \%$ and a 30 -day mortality rate of less than $3 \%$. This is due to the careful selection of patients and the frequent implementation of TIPS at large centers [34]. The initially reported, relatively high mortality rate of the intervention was due to poor patient selection (high MELD or APACHE II score) and/or the treatment of patients with high bilirubin values. Today the TIPS intervention is considered a safe method with a low mortality rate, particularly in the case of elective procedures. An analysis was able to show that the rate of fatal complications depends on the number of TIPS procedures performed at the particular hospital: $3 \%$ in the case of fewer than 150 interventions compared to $1.4 \%$ in the case of more TIPS placement procedures [11].

Comparison of the patency rates after implantation of wall stents (BMSs: bare metal stents) with those after insertion of a stent graft shows significantly better primary and assisted primary patency rates for the latter so that stent grafts have since become the standard [2, 35, 36]. The American Association for the Study of Liver Diseases (AASLD) has consequently recommended primarily using covered stents for the TIPS procedure [11]. The primary 2-year shunt dysfunction rate is $24-44 \%$ for stent grafts and approximately $64 \%$ for BMSs. Although patients with a BMS require more re-interventions, the secondary patency rate in both groups after 5 years is consistently greater than $95 \%$. However, it must be taken into consideration that a stent graft can be 

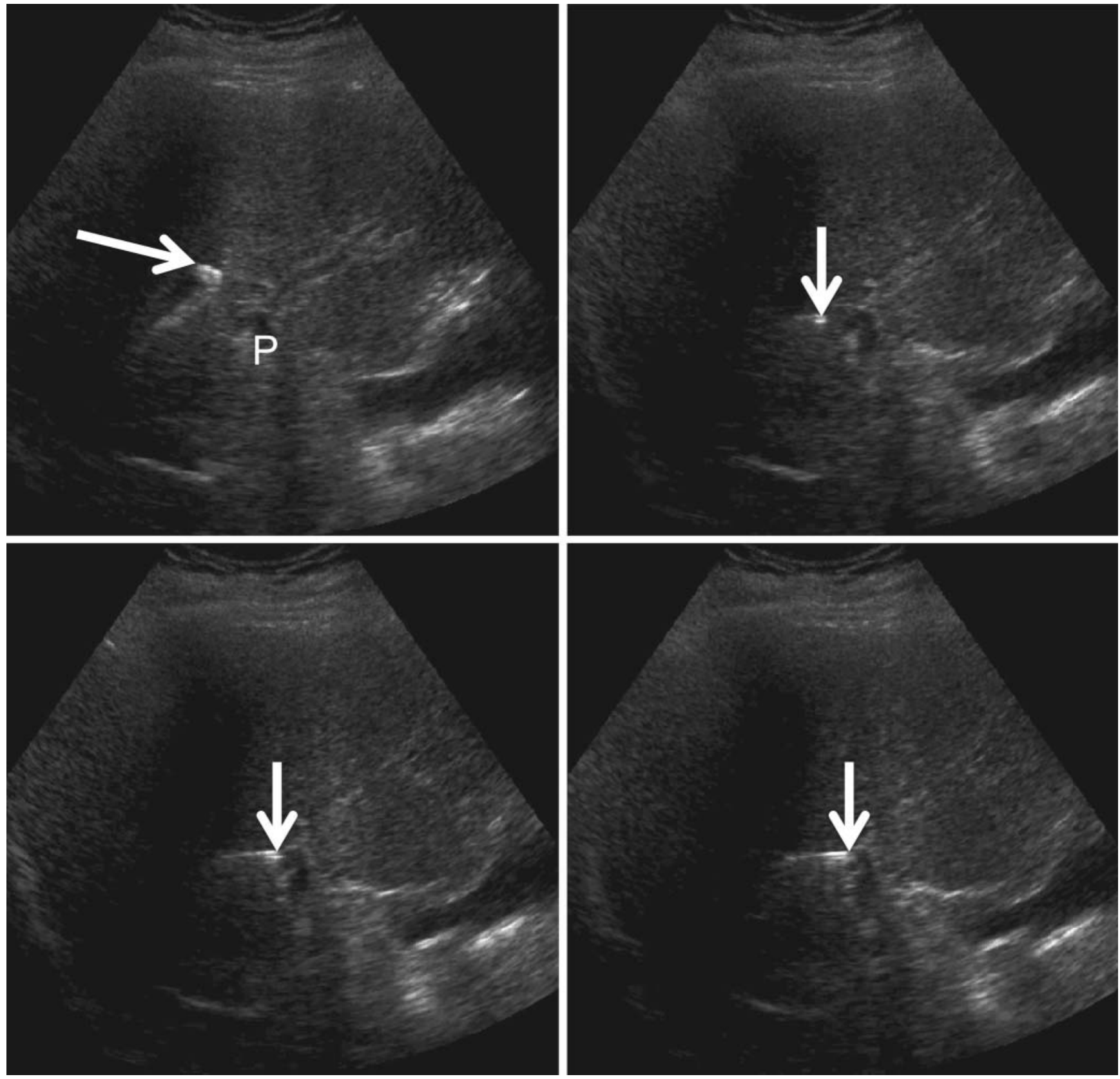

- Fig. 2 Left upper image: Under sonographic guidance, the needle with the curved guidewire tip outside (arrow) is withdrawn until the planned puncture site is reached ( $\mathrm{P}=$ targeted portal vein branch). Following images: the guidewire is then withdrawn into the needle (arrow) which is advanced under sonographic guidance and the portal vein branch is punctured.

inserted into an existing BMS in the long-term in the case of repeat interventions after BMS placement.

\section{Survival rate}

Patient age is a highly significant predictor of survival, i. e., advanced age at the time of TIPS placement is a negative predictor for survival [37]. The Child-Pugh score is also an important predictor of a patient's survival time [38, 39]. In particular, patients with Child-Pugh score $C$ have an increased mortality rate [40].

Another important parameter for the survival of patients with liver cirrhosis is the MELD score. Therefore, in the study by Tzeng et al. [39] the mortality rate after 1 year was 3.6 times higher in the case of a MELD score of $>20$ points compared to $<15$ points and was even 8 times higher after 30 days. On the whole, it is not surprising that survival decreases with an increasing Child-Pugh or MELD score because these scores reflect the severity of the underlying liver disease.

It is also stated that survival depends greatly on the indication and the 1-year mortality in patients treated for ascites was significantly lower than in those with variceal bleeding [41, 42]. 

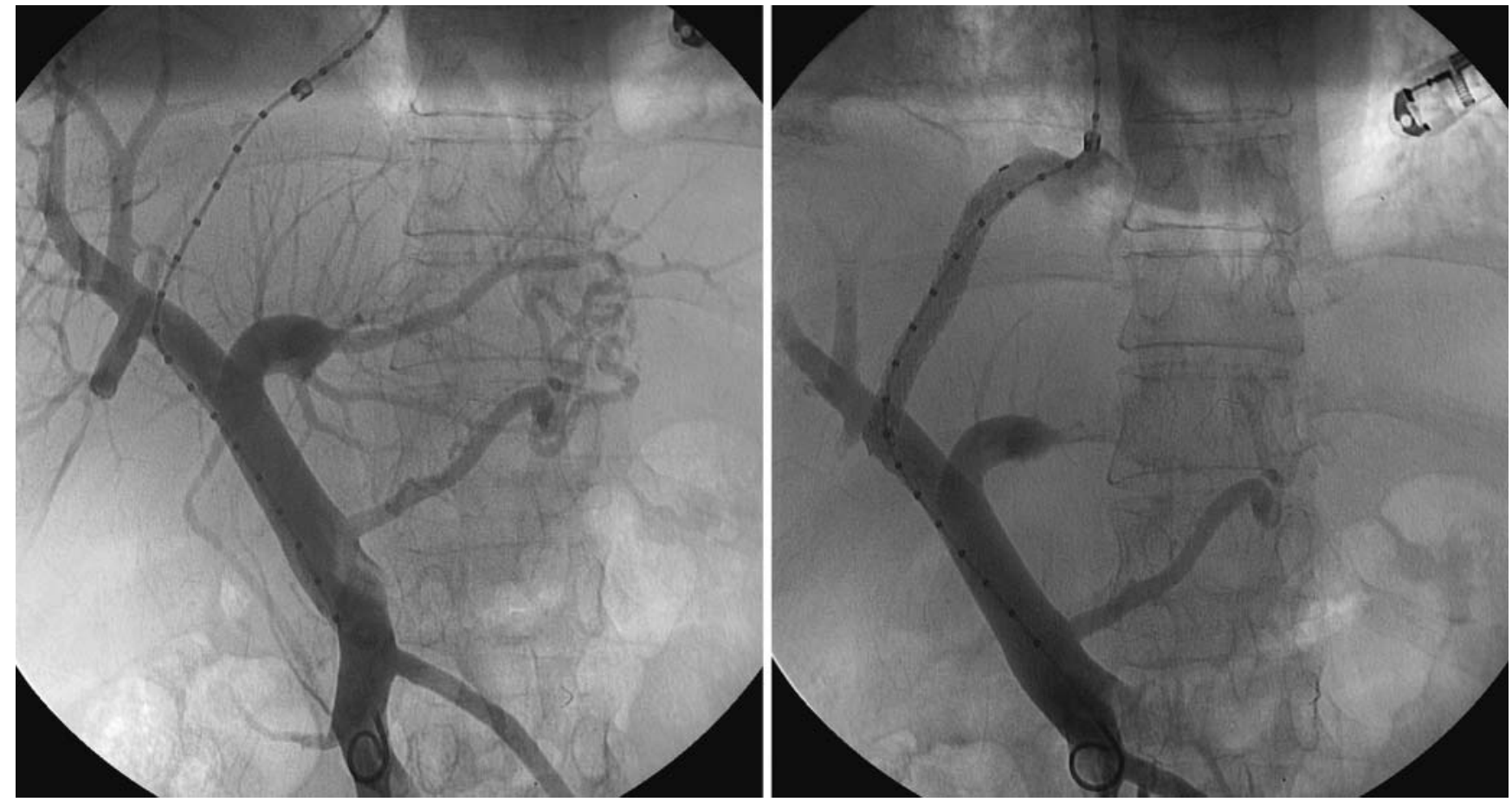

- Fig. 3 Left image: after a guidewire is introduced, the needle is exchanged for a calibrated catheter for diagnostic purposes and pressure measurements. Right image: Control study after TIPS placement and balloon dilatation.

\section{Complications}

Complications as a result of the intervention are (intraperitoneal) bleeding, perforation of the liver capsule, vessels (portal vein, hepatic artery) or bile ducts. The latter can result in the formation of fistulas and was viewed as a risk factor for in-stent stenosis in the case of BMSs. The incidence of these complications is specified as $0.5-4.3 \%$ [43]. Early stent thromboses or stent migration as well as (usually self-limiting) intravascular hemolysis and stent infection are possible but are extremely rare in the case of stent grafts. The high rate of early thrombosis of $10-15 \%$ reported in individual cases when using BMS was not seen in most studies.

A clinically relevant complication is the worsening or development of hepatic encephalopathy which is reported in $20-31 \%$ of interventions [17, 43, 44]. Hypoalbuminemia, advanced age, preexisting encephalopathy are specified as predisposing factors $[45,46]$.

\section{TIPS and liver function}

TIPS placement reduces or normalizes portal hypertension but results in worsening of liver function. Even though the TIPS procedure does not result in clinically relevant liver failure in more than $90 \%$ of patients with a bilirubin value of less than $3 \mathrm{mg} / \mathrm{dl}$ [47], the bilirubin and INR values increase as a sign of liver dysfunction while there is a reduction in albumin values [7]. The decreased portal-venous perfusion of the liver is primarily considered to be the cause. New or worsening hepatic encephalopathy can also be caused by liver insufficiency or be a direct effect of the shunt. The two mechanisms cannot be differentiated from one another.

\section{TIPS and cardiac function}

In addition to acute effects on liver function, TIPS can also cause long-term cardiac effects. Therefore, changes in systemic hemodynamics can result in cardiac overload and the development of pulmonary hypertension within 5 years of a TIPS procedure [48].

\section{Key Points}

Besides the TIPS procedure, sufficient and effective treatment of complications related to portal hypertension is currently limited to the use of acute vasoconstrictors of the mesenteric vasculature (e. g. Terlipressin), classic prevention of bleeding with nonselective beta blockers (NSBBs), or endoscopic treatment. NSBBs, which were introduced approximately 35 years ago by Lebrec and colleagues, reduce the portal-venous inflow by lowering the cardiac ejection fraction and increasing mesenteric vascular tone. NSBBs can lower the portal pressure sufficiently to prevent variceal bleeding. In combination with endoscopic therapy, they reduce the rate of rebleeding and improve the survival of patients with cirrhosis and varices and of patients with acute-to-chronic liver failure (ACLF) [5]. However, this also means that patients under primary or secondary prophylaxis with NSBBs can still bleed and experience liver disease progress. In approximately half of patients, NSBBs do not yield the desired hemodynamic results and do not prevent early rebleeding [17]. In addition, the use of NSBBs in treatment-refractory ascites can have a damaging effect probably due to the restriction of the cardiac ejection fraction. 


\section{TIPS and variceal bleeding}

TIPS placement is the most effective measure for preventing variceal bleeding. However, due to the invasive nature and the potential complications, the TIPS procedure is not recommended for primary prophylaxis [10]. After initial variceal bleeding, the TIPS procedure is only recommended in high-risk patients, i. e., patients in Child-Pugh stage B with active bleeding on endoscopy, patients in Child-Pugh stage $C$ with less than 14 points in the early TIPS situation (in the first 72 hours after bleeding) [13] or in patients with a portocaval pressure gradient of more than $20 \mathrm{~mm} \mathrm{Hg}$ [49]. The TIPS survival advantage in high-risk patients has been shown in multiple studies [13-15]. The reason for this survival advantage may be the prevention of decompensation as a result of the simultaneous treatment of ascites, bacterial translocation, and systemic inflammation.

In patients not fulfilling the above criteria, studies could not show a survival advantage as a result of the TIPS procedure even if rebleeding de facto no longer occurred [50]. The main complications in non-TIPS patients were early rebleeding and a lack of response to NSBBs [17]. Therefore, in patients who are experiencing bleeding despite primary prophylaxis (clinical lack of response to NSBBs), a combination of NSBBs and endoscopic therapy will probably not yield an advantage and the TIPS procedure should be given preference as the first-line therapy. Also in the case of stent grafts, no effect on the survival of patients could be shown despite the better control of rebleeding. On the contrary, a higher rate of hepatic encephalopathy was reported [17] with it being slightly strange that this was specified particularly for small stent diameters [17] while no statistical differences were reported in the case of larger stent diameters [51].

Recurrent bleeding is definitely an indication for TIPS placement as long as it is technically feasible and there is a sufficient hepatic reserve [10] ( $\triangleright$ Table 1 ). A further indication without a possible alternative is bleeding refractory to other treatments. However, there has been significant improvement in the treatment of variceal bleeding in the last 30 years so that treatmentrefractory bleeding is currently rather rare.

Therefore, while the value of the TIPS procedure in recurrent and treatment-refractory new bleeding is clear, the value of early use in the case of initial variceal bleeding has not be definitively proven and is recommended only in high-risk patients ( $\triangleright$ Table 1 ).

\section{Treatment-refractory ascites and hepatorenal syndrome}

The TIPS procedure gives patients with treatment-refractory ascites a survival advantage particularly in studies with stent grafts $[18,52,53]$. In a retrospective analysis [9], stent grafts were significantly superior to metal stents (bare metal stents). There is also a survival advantage for TIPS implantation with PTFE-covered stents compared to paracentesis [54]. However, this advantage decreases in the second year after TIPS implantation possibly due to the deteriorating influence of TIPS on cardiac factors. Therefore, a TIPS procedure should be considered primarily as a bridging therapy prior to liver transplantation in treatment-refractory ascites.
Patients with treatment-refractory ascites usually present with low serum sodium and reduced sodium elimination. They often develop acute renal insufficiency and hepatorenal syndrome (HRS) [8]. These patients can benefit from TIPS placement [23]. A bilirubin value $>5 \mathrm{mg} / \mathrm{dl}$, diastolic dysfunction, bacterial infection, and hepatic encephalopathy are specified as contraindications in this study. In addition, this improvement in renal function can result in a lower transplantation probability particularly in countries with a MELD score-based classification system (e. g. Eurotransplant) on the one hand because the creatinine value, a parameter determining the MELD score, improves and on the other hand because the TIPS procedure can result in cardiac worsening and pulmonary hypertension in the long-term making liver transplantation impossible. Although some patients with hepatorenal syndrome can benefit from a TIPS procedure, it should be used conservatively in this disease due to the high risk primarily for the development of hepatic encephalopathy.

\section{Conflict of Interest}

The authors declare that they have no conflict of interest.

\section{Widmung}

Diese Arbeit ist Herrn Univ.-Prof. Dr. med. Hans Heinz Schild gewidmet, bei dem wir uns herzlich für die langjährige und stete Unterstützung in allen klinischen und wissenschaftlichen Belangen bedanken möchten.

\section{Acknowledgement}

TIPS or no TIPS, we thank Univ.-Prof. Dr. Hans H. Schild and dedicate this article to him for his tips and support.

\section{References}

[1] Rossle M, Richter GM, Noldge G et al. New non-operative treatment for variceal haemorrhage. [letter]. Lancet 1989; 2: 153

[2] Bureau C, Pagan JC, Layrargues GP et al. Patency of stents covered with polytetrafluoroethylene in patients treated by transjugular intrahepatic portosystemic shunts: long-term results of a randomized multicentre study. Liver Int 2007; 27: $742-747$

[3] Henderson JM. Surgery versus transjugular intrahepatic portal systemic shunt in the treatment of severe variceal bleeding. Clin Liver Dis 2006; 10: $599-612$, ix

[4] Rossle M. TIPS: 25 years later. J Hepatol 2013; 59: 1081-1093

[5] Trebicka J, von Heydebrand M, Lehmann J et al. Assessment of response to beta-blockers by expression of betaArr2 and RhoA/ROCK2 in antrum mucosa in cirrhotic patients. J Hepatol 2016; 64: 1265-1273

[6] Villanueva C, Albillos A, Genesca J et al. Development of hyperdynamic circulation and response to beta-blockers in compensated cirrhosis with portal hypertension. Hepatology 2016; 63: 197-206

[7] Berres ML, Lehmann J, Jansen C et al. Chemokine (C-X-C motif) ligand 11 levels predict survival in cirrhotic patients with transjugular intrahepatic portosystemic shunt. Liver Int 2016; 36: 386-394

[8] Allegretti AS, Ortiz G, Cui J et al. Changes in Kidney Function After Transjugular Intrahepatic Portosystemic Shunts Versus Large-Volume Paracentesis in Cirrhosis: A Matched Cohort Analysis. Am J Kidney Dis 2016; 68: 381-391 
[9] Tan HK, James PD, Sniderman KW et al. Long-term clinical outcome of patients with cirrhosis and refractory ascites treated with transjugular intrahepatic portosystemic shunt insertion. J Gastroenterol Hepatol 2015; 30: 389-395

[10] de Franchis R. Expanding consensus in portal hypertension: Report of the Baveno VI Consensus Workshop: Stratifying risk and individualizing care for portal hypertension. J Hepatol 2015; 63: 743-752

[11] Boyer TD, Haskal Z]. The Role of Transjugular Intrahepatic Portosystemic Shunt (TIPS) in the Management of Portal Hypertension: update 2009. Hepatology 2010; 51: 306

[12] Garcia-Pagan JC, Caca K, Bureau C et al. Early use of TIPS in patients with cirrhosis and variceal bleeding. N Engl J Med 2010; 362: 2370-2379

[13] Garcia-Pagan JC, Di Pascoli M, Caca K et al. Use of early-TIPS for high-risk variceal bleeding: results of a post-RCT surveillance study. J Hepatol 2013; 58: $45-50$

[14] Thabut D, Rudler M, Lebrec D. Early TIPS with covered stents in high-risk patients with cirrhosis presenting with variceal bleeding: Are we ready to dive into the deep end of the pool? J Hepatol 2011; 55: 1148-1149

[15] Deltenre P, Trepo E, Rudler M et al. Early transjugular intrahepatic portosystemic shunt in cirrhotic patients with acute variceal bleeding: a systematic review and meta-analysis of controlled trials. Eur J Gastroenterol Hepatol 2015; 27: e1 -e9

[16] Hernández-Gea V, Bureau C. Practice makes better: TIPS procedures in referral centers [editorial]. Hepatology 2017; 67: 473-475

[17] Sauerbruch T, Mengel M, Dollinger M et al. Prevention of Rebleeding From Esophageal Varices in Patients With Cirrhosis Receiving SmallDiameter Stents Versus Hemodynamically Controlled Medical Therapy. Gastroenterology 2015; 149: 660-668.e1

[18] Salerno F, Camma C, Enea M et al. Transjugular intrahepatic portosystemic shunt for refractory ascites: a meta-analysis of individual patient data. Gastroenterology 2007; 133: 825 - 834

[19] Garcia-Pagan JC, Heydtmann M, Raffa S et al. TIPS for Budd-Chiari syndrome: long-term results and prognostics factors in 124 patients. Gastroenterology 2008; 135: 808-815

[20] Rossle M, Grandt D. TIPS: an update. Best Pract Res Clin Gastroenterol 2004; 18: $99-123$

[21] Kori I, Bar-Zohar D, Carmiel-Haggai M et al. Budd-Chiari syndrome and acute portal vein thrombosis: management by a transjugular intrahepatic portosystemic shunt (TIPS) and portal vein interventions via a TIPS. J Gastrointest Surg 2006; 10: 417-421

[22] Ferro C, Rossi UG, Bovio G et al. Transjugular intrahepatic portosystemic shunt, mechanical aspiration thrombectomy, and direct thrombolysis in the treatment of acute portal and superior mesenteric vein thrombosis. Cardiovasc Intervent Radiol 2007; 30: 1070 - 1074

[23] Brensing KA, Textor J, Perz J et al. Long term outcome after transjugular intrahepatic portosystemic stent-shunt in non-transplant cirrhotics with hepatorenal syndrome: a phase II study. Gut 2000; 47: 288-295

[24] Tsauo J, Weng N, Ma H et al. Role of Transjugular Intrahepatic Portosystemic Shunts in the Management of Hepatopulmonary Syndrome: A Systemic Literature Review. J Vasc Interv Radiol 2015; 26: 1266 - 1271

[25] Tsauo J, Shin JH, Han K et al. Transjugular Intrahepatic Portosystemic Shunt for the Treatment of Chylothorax and Chylous Ascites in Cirrhosis: A Case Report and Systematic Review of the Literature. J Vasc Interv Radiol 2016; 27: $112-116$

[26] Boyer TD. Transjugular intrahepatic portosystemic shunt: current status. Gastroenterology 2003; 124: 1700-1710

[27] Clark TW. Stepwise placement of a transjugular intrahepatic portosystemic shunt endograft. Tech Vasc Interv Radiol 2008; 11: 208 - 211

[28] Fidelman N, Kwan SW, LaBerge JM et al. The transjugular intrahepatic portosystemic shunt: an update. Am J Roentgenol 2012; 199: 746-755

[29] Boyvat F, Aytekin C, Harman A et al. Transjugular intrahepatic portosystemic shunt creation in Budd-Chiari syndrome: percutaneous ultra- sound-guided direct simultaneous puncture of the portal vein and vena cava. Cardiovasc Intervent Radiol 2006; 29: 857-861

[30] Boyvat F, Harman A, Ozyer U et al. Percutaneous sonographic guidance for TIPS in Budd-Chiari syndrome: direct simultaneous puncture of the portal vein and inferior vena cava. Am J Roentgenol 2008; 191: 560 564

[31] Chen S, Li X, Wei B et al. Recurrent variceal bleeding and shunt patency: prospective randomized controlled trial of transjugular intrahepatic portosystemic shunt alone or combined with coronary vein embolization. Radiology 2013; 268: 900 - 906

[32] Lakhoo J, Bui JT, Zivin SP et al. Root Cause Analysis of Rebleeding Events following Transjugular Intrahepatic Portosystemic Shunt Creation for Variceal Hemorrhage. J Vasc Interv Radiol 2015; 26: 1444-1453

[33] Blue RC, Lo GC, Kim E et al. Transjugular Intrahepatic Portosystemic Shunt Flow Reduction with Adjustable Polytetrafluoroethylene-Covered Balloon-Expandable Stents Using the "Sheath Control" Technique. Cardiovasc Intervent Radiol 2016; 39: 935 -939

[34] Rossi P, Salvatori FM, Fanelli F et al. Polytetrafluoroethylene-covered nitinol stent-graft for transjugular intrahepatic portosystemic shunt creation: 3-year experience. Radiology 2004; 231: 820-830

[35] Yang Z, Han G, Wu Q et al. Patency and clinical outcomes of transjugular intrahepatic portosystemic shunt with polytetrafluoroethylene-covered stents versus bare stents: a meta-analysis. J Gastroenterol Hepatol 2010; 25: $1718-1725$

[36] Perarnau JM, Le Gouge A, Nicolas C et al. Covered vs. uncovered stents for transjugular intrahepatic portosystemic shunt: a randomized controlled trial. J Hepatol 2014; 60: 962 - 968

[37] Pan J], Chen C, Caridi JG et al. Factors predicting survival after transjugular intrahepatic portosystemic shunt creation: 15 years' experience from a single tertiary medical center. J Vasc Interv Radiol 2008; 19: $1576-1581$

[38] Brensing KA, Horsch M, Textor ] et al. Hemodynamic effects of propranolol and nitrates in cirrhotics with transjugular intrahepatic portosystemic stent-shunt. Scand J Gastroenterol 2002; 37: 1070 - 1076

[39] Tzeng WS, Wu RH, Lin CY et al. Prediction of mortality after emergent transjugular intrahepatic portosystemic shunt placement: use of APACHE II, Child-Pugh and MELD scores in Asian patients with refractory variceal hemorrhage. Korean J Radiol 2009; 10: 481 - 489

[40] Harrod-Kim P, Saad WE, Waldman D. Predictors of early mortality after transjugular intrahepatic portosystemic shunt creation for the treatment of refractory ascites. J Vasc Interv Radiol 2006; 17: 1605-1610

[41] Ferral H, Vasan R, Speeg KV et al. Evaluation of a model to predict poor survival in patients undergoing elective TIPS procedures. J Vasc Interv Radiol 2002; 13: 1103-1108

[42] Schepke M, Roth F, Fimmers R et al. Comparison of MELD, Child-Pugh, and Emory model for the prediction of survival in patients undergoing transjugular intrahepatic portosystemic shunting. Am J Gastroenterol 2003; 98: 1167 - 1174

[43] Ripamonti R, Ferral H, Alonzo M et al. Transjugular intrahepatic portosystemic shunt-related complications and practical solutions. Semin Intervent Radiol 2006; 23: 165 - 176

[44] Riggio O, Nardelli S, Moscucci F et al. Hepatic encephalopathy after transjugular intrahepatic portosystemic shunt. Clin Liver Dis 2012; 16: $133-146$

[45] Riggio O, Angeloni S, Salvatori FM et al. Incidence, natural history, and risk factors of hepatic encephalopathy after transjugular intrahepatic portosystemic shunt with polytetrafluoroethylene-covered stent grafts. Am J Gastroenterol 2008; 103: 2738-2746

[46] Masson S, Mardini HA, Rose JD et al. Hepatic encephalopathy after transjugular intrahepatic portosystemic shunt insertion: a decade of experience. QJM 2008; 101: 493 - 501

[47] Luca A, Miraglia R, Maruzzelli L et al. Early Liver Failure after Transjugular Intrahepatic Portosystemic Shunt in Patients with Cirrhosis with Model 
for End-Stage Liver Disease Score of 12 or Less: Incidence, Outcome, and Prognostic Factors. Radiology 2016; 280: 622 - 629

[48] Wannhoff A, Hippchen T, Weiss CS et al. Cardiac volume overload and pulmonary hypertension in long-term follow-up of patients with a transjugular intrahepatic portosystemic shunt. Aliment Pharmacol Ther 2016; 43: $955-965$

[49] Monescillo A, Martinez-Lagares F, Ruiz-del-Arbol L et al. Influence of portal hypertension and its early decompression by TIPS placement on the outcome of variceal bleeding. Hepatology 2004; 40: $793-801$

[50] Qi X, Tian Y, Zhang W et al. Covered TIPS for secondary prophylaxis of variceal bleeding in liver cirrhosis: A systematic review and meta-analysis of randomized controlled trials. Medicine (Baltimore) 2016; 95: e5680
[51] Holster IL, Tjwa ET, Moelker A et al. Covered transjugular intrahepatic portosystemic shunt versus endoscopic therapy + beta-blocker for prevention of variceal rebleeding. Hepatology 2016; 63: 581 - 589

[52] Bai M, Qi XS, Yang ZP et al. TIPS improves liver transplantation-free survival in cirrhotic patients with refractory ascites: an updated meta-analysis. World J Gastroenterol 2014; 20: $2704-2714$

[53] Bureau C, Thabut D, Oberti F et al. Transjugular Intrahepatic Portosystemic Shunts With Covered Stents Increase Transplant-Free Survival of Patients With Cirrhosis and Recurrent Ascites. Gastroenterology 2017; 152: $157-163$

[54] Gaba RC, Parvinian A, Casadaban LC et al. Survival benefit of TIPS versus serial paracentesis in patients with refractory ascites: a single institution case-control propensity score analysis. Clin Radiol 2015; 70: e51 - e57 